\title{
The Influence of Customer Engagement in Customers' Behavioral Intention on Staycation: The Experiential Marketing Perspectives Moderated by Health Risk and Financial Risk
}

\author{
Resky Oktavia ${ }^{1, *}$ Nurdin Sobari $^{2}$ \\ ${ }^{1}$ Faculty of Economics and Business, University of Indonesia, Jakarta, Indonesia, resky.oktavia@ui.ac.id \\ ${ }^{2}$ Faculty of Economics and Business, University of Indonesia, Jakarta, Indonesia, nurdin.sobari@ui.ac.id
}

\begin{abstract}
During the covid-19 pandemic, staycation is likely to play a key role in tourism industry as an alternative solution. Nevertheless, among the abundance study in tourism industry, research on staycation depicted in experiential marketing remains nebulous. Drawn from the experiential marketing perspectives, this study highlighted customer engagement's influence upon customer's behavioral intention on doing staycation which mediated by customer experience and customer identification. However during the pandemic, perceived risk such as health risk and financial risk plays a significant role in shaping customer behavior during decisionmaking process. Thus, the moderating role of both health risk and financial risk from customer experience and customer identification toward customers' behavioral intention were also be examined in this study. The model was tested toward 249 respondents who have done staycation at least once within 7 months ever since the first case of covid-19 in Indonesia was announced. The collected data then examined using Structural Equation Modelling (SEM) Lisrel. Findings showed that both affective and cognitive engagement has positive significant influence toward customer experience, but negatively affect customer identification. However, behavioral engagement positively influence customer identification but has negative significant influence toward customer experience. In addition, health risk has negative influence as moderating variable but positively influence behavioral intention directly. Besides, financial risk significantly influence behavioral intention directly, and influence customer identification positively, but has no significant influence toward customer experience. The theoretical and practical implications to encourage tourism stakeholders to stimulate customer experience and customer identification by enhancing their engagement during staycation are discussed.
\end{abstract}

Keywords: Experiential Marketing, Customer Engagement, Customer Experience, Staycation, Perceived Risk, Health Risk, Financial Risk.

\section{INTRODUCTION}

The Covid-19 pandemic has at least infected more than 34 million people worldwide with more than 1 million deaths ${ }^{[1]}$. It has driven major changes within government policies worldwide, the global economy and health system in particular ${ }^{[2]}$ which resulted in an economic downturn. An economic downturn, as Hultman et.al said (2015) provides both opportunities and threats at the same time ${ }^{[3]}$. In fact, during the period before the pandemic, a lot of industries are in a fast developing pace, including demand for global tourism [4]. However various restrictions on travel and instructions for physical distancing have been ordered from the government ${ }^{[2]}$, thus it is inevitable for the tourism industry to become one of the most affected industries massively. Whereas the tourism sector has a significant contribution to the modern economic system ${ }^{[5]}$ and represents $30 \%$ of service exports in the world ${ }^{[6]}$ however ironically it has become one of the reasons for the rapid spread of the virus itself ${ }^{[7]}$. There have been calls for recent studies on covid-19 and tourism to use the emerging pandemic as a transformative opportunity [7]. Therefore, it is important for researcher to not only use the pandemic as a context on replicating prior studies ${ }^{[7]}$, but also to go further by contributing novelty for a better transformation in this industry.

Staycation emerges as one valuable alternative that has great potential and opportunities to be explored and proven to have succeeded in saving the tourism sector in the US during the economic crisis in $2008{ }^{[8]}$. Yesawich (2010) suggests that a staycation is an overnight vacation trip with a distance of 50 miles from the place of residence ${ }^{[8]}$. Despite the valuable conceptual ideas, it is still scarce to find answers to what offerings do customers get from staycation. One of them is that consumers will receive benefits in experiences that are 
personal and only appear in the minds of consumers who have been involved intellectually, physically, emotionally, and or at a spiritual level ${ }^{[9]}$. A pleasant experience will stay in the minds of consumers for a long time and influence their behavior. Therefore, regulating the environment that shapes this experience is a major key to the survival and competitive advantage of tourism industry players ${ }^{[3]}$. However, the empirical study remains limited on elaborating the importance of customer experiences and customer engagement to increase competitive advantage for staycation businesses.

Therefore, Ahmad Rather [9] suggests how an experiential marketing perspective is a vital issue to be considered in the tourism industry. The prior study offers a framework where customer engagement has an influence on customer experience and customer identification and as a result, there is behavioral intention that can help stakeholders predict patterns of changing consumer behavior. Based on a survey conducted by PWC ${ }^{[10]}, 73 \%$ of respondents think that customer experience is an important factor in shaping customer's purchasing decisions. The tourism industry oftentimes involves consumers in the production process (co-create), thus consumers must be engaged first in order to co-create a good experience to later influence their behavioral re-intention such as revisit intention and word-of-mouth. Consumers who are already engaged are expected to have an important role in co-creating customer experience and value ${ }^{[11]}$. In previous empirical studies, it is more familiar to find customer experience as an independent variable that affects customer engagement, but in fact the two elements (customer engagement and customer experience) play a complementary role in an upward spiraling loop. Consumers who get a good co-customer experience will find it easier to be engaged, and on the other hand, the more engaged the consumer is, the better the experience they will have later ${ }^{[12]}$

The tourism sector is familiar with various risks during travel (Kozak et al., 2007). In various studies on consumer behavior, the theory of perceived risk refers to consumer behavior when making decisions before purchasing because various uncertainties have potential negative consequences. Perceived risk itself comes from the consequences of uncertainty and cannot be anticipated when purchasing a product (Bauer, 1960; Rehman et. Al., 2020). The theory of perceived risk itself has been discussed since the 1960s (Buratti et al, 2019) where various studies related to tourism tested how perceived risk affects their decisions on travel (Adam, 2015, Lepp, 2011). In the midst of pandemic conditions, the impact of health risks will be the main concern of consumers before conducting a staycation. Additionally, to the contraction of various economic activities in the midst of crisis during the pandemic, consumers are also faced with other obstacles such as financial issues, thus financial risk is also an important element in this research.
Built upon these backgrounds, the authors want to close the gap by presuming that not only customer engagement and customer experience [9] should be regarded as an integrated strategic and core aspects to promote staycation, but also a configured consideration of health risk and financial risk conditions could also lead to desired behavioral responses in staycation.

Therefore, the researchers suggests to address problems described as follows:

1. Does customer engagement have an influence on customer experience and customer identification in staycation?

2. Do customer experience and customer identification have an influence on behavioral intention in staycation?

3. Does customer experience have an influence on customer identification in staycation?

4. Do health risk and financial risk have a direct and moderating influence toward behavioral intention in staycation?

\section{LITERATURE REVIEW}

\subsection{Staycation}

Staycation, first coined by Terry Masey (2013) ${ }^{[8]}$, is a period when an individual or family stays at home and participates in activities within driving range where they don't need to spend overnight (Suau-Sanchez et. al, 2020). In this research, researchers used the term staycation defined by Yesawich (2010) which defines staycation as an overnight travel within 50 miles from one's home ${ }^{[8]}$. Based on research ${ }^{[9]}$ which showcase significance relation between customer engagement, customer relationship and customer identification toward customer behavior, the use of experiential marketing perspective in staycation is essential for maintaining stakeholder's competitive advantage in developing value creation in tourism industry. However, as highlighted in this research, the use of risk assessment will certainly give valuable implication for this industry ${ }^{[4]}$ especially during pandemic.

\subsection{Customer Engagement (CE)}

Customer engagement is well known as the positive validation customer has toward brands, related to cognitive, emotional, and behavioral during consumerbrand interaction ${ }^{[9]}$. There are three main dimensions that will have to be sharpen by tourism stakeholders in order to be more engaged with their customers; cognitive, affective, and behavior ${ }^{[9]}$. The level of elaboration and thinking processes customers had towards a brand during the customer-brand interaction, or known as cognitive aspect, is believed to be one of the dimensions that should be developed by stakeholders. Other aspects are affective, a positive 
influence a brand has in the customer mind, and behavioral dimension which shows the level of energy, effort and time spent by the customer in the interaction.

\subsection{Customer Experience (CX)}

In understanding customer experience, there are 3 different phases of purchasing that have to be kept in mind (Verhoef et al., 2009); pre-purchase, purchase, and post-purchase. These are important to be acknowledge since customer experience is a developing senses response; affective, cognitive, relational, as well as one's behavior toward a brand (staycation) throughout the journey during those three phases, as well as the customer judgment of the whole journey experience as response that occurs at the same time ${ }^{[9]}$. Upon this understanding, experiential marketing will be categorized in five branches [9]. Sense marketing focuses on one's senses by increasing the stimulus of experiences that related to sight, taste, touch, sound, and smell. Feel marketing enriching customer's emotion and deepest feelings by enhancing affective experiences that range from subtle positive feelings towards a staycation to strong feelings filled with pride and joy. Think marketing attracts consumers' attention by enhancing cognitive-based and problem-solving experiences that bind consumers in a harmonious relationship between humans and nature. Act Marketing focuses on physical experiences where consumers are shown interactions and alternative lifestyles, as well as various alternative ways of doing things. Last is relate marketing which increases consumer desire for self-improvement, which relates to the need to be recognized positively by others.

$\mathrm{H}_{1}$ : Cognitive behavior has a significant positive effect on customer experience in staycations

$\mathrm{H}_{3}$ : Affective engagement has a significant positive effect on customer experience in staycations

$\mathrm{H}_{5}$ : Behavioral engagement has a significant positive effect on customer experience in staycations

$\mathrm{H}_{11}$ : Customer experience has a significant positive effect on customer identification in staycation

\subsection{Customer Identification (CI)}

Customer-brand relationship has been depicted to have a strong connection with experiential marketing. The relation a customer has toward a brand rooted within believes that there is personal and social identity which built customer self-images ${ }^{[9]}$. This psychological state of ones' feeling, acknowledgment, and their judgment of ownership upon brands is identified as customer identification [3]. Earlier, Kumar \& Kaushik (2018) explains beforehand how customer-brand relationships cognitively, affectively, and emotionally will strengthen their identification toward brands in the long term.
$\mathrm{H}_{2}$ : Cognitive engagement has a significant positive effect on customer identification in staycation

$\mathrm{H}_{4}$ : Affective engagement has a significant positive effect on customer identification in staycation

$\mathrm{H}_{6}$ : Behavioral engagement has a significant positive effect on customer identification in staycation

\subsection{Behavioural Intention}

The condition to be engaged in a behavior has been long known as behavioral intention [9] which later on classified as four distinct categories as purchase intention, price sensitivity, complaining behavior, and word of mouth (Zeithaml, Berry, dan Parasuraman, 1996; Rather, 2010).

$\mathrm{H}_{7}$ : Customer experience has a significant positive effect on behavioral intention in a staycation

$\mathrm{H}_{8}$ : Customer identification has a significant positive effect on behavioral intention in staycations

\subsection{Health Risk on Tourism}

In visiting a destination, one of the prominent factors in shaping customer decisions is their perception about the perceived risk and security during the trip ${ }^{[13]}$. Several empirical studies have disclosed the degree of perceived risk a customer has which will influence their behavioural intention (An, Lee, \& Noh, 2010; Artuger, 2015; Cetinsoz \& Ege, 2013) one way or another. The possibility of incidents, climate change, natural disasters, harmful diseases which generally will damage one's body [4]. Accordingly, if stakeholders could manage to control these in delivering their products, it is likely for them to gain consumer trust, satisfactory level, as well customer loyalty which eventually will lead to value creation and profit margin ${ }^{[4]}$.

$\mathrm{H}_{9}$ : Health Perceived Risk has an influence on behavioral intention in a staycation

$\mathrm{H}_{9 \mathrm{a}}$ : Health Perceived Risk moderates between customer experience and behavioral intention in staycations

$\mathrm{H}_{9 \mathrm{~b}}$ : Health Perceived Risk moderates customer identification on behavioral intention in staycations

\subsection{Financial Risk on Tourism}

Understanding financial risk has been long discussed, it has been defined as risk obtained by someone when he/she purchases a product, whether goods or service, which price doesn't match the value gained [13]. However, financial risk in this study refers to the definition coined by $\mathrm{Al}$ Ansi ${ }^{[4]}$ who explained that financial risk is the possibility that the value of a 
product does not meet its financial price and could have been bought with lower price somewhere else.

$\mathrm{H}_{10}$ : Financial Perceived Risk has a significant positive effect on behavioral intention in staycations

$\mathrm{H}_{10 \mathrm{a}}$ : Financial Perceived Risk moderates between customer experience and behavioral intention in staycations

$\mathrm{H}_{10 \mathrm{~b}}$ : Financial Perceived Risk moderates customer identification on behavioral intention in staycations

\subsection{Strategic Experiential Modules (SEMs)}

Strategic Experiential Modules is a strategic module that managers can use to create various customer experiences for their customers ${ }^{[14]}$. Schmitt explained that in this module there are sensory experiences (sense), affective experiences (feel), creative thinking experiences (think), physical experiences (act), to social-identity experiences resulting from relationships with certain reference groups or cultures (relate); all of which can be arranged in experiential marketing. In its implementation, managers can use "experience providers", which include communication, verbal and visual identities, product existence, co-branding, spatial environment, electronic media, and individuals (people).

\subsection{Service Dominant (SD) Logic}

Service dominant theory was first introduced by Vargo and Lusch in their research in $2004{ }^{[9]}$ where both of them proposed an inverse interpretation of traditional economic activities which is usually explained from the point of view of goods production/companies. From the viewpoint of service dominant logic, contemporary consumers are proactively contributing to their own service experience (Vargo \& Lusch, 2016; Hollebeek et al., 2016) as a fundamental basis in the process of exchanging values. As proactive contributors to their own experiences, consumers oftentimes engaged in brand-related activities such as discussions, helping other consumers, co-innovating company offerings, therefore adding a level of service collaboration and personalization ${ }^{[3]}$ will give competitive advantages to stakeholders.

\subsection{Prospect Theory \& Complexity Theory}

Camerer (2005) ${ }^{[4]}$ explained that prospect theory is commonly used in conducting research models in consumer behavior because this theory is based on real life choices and not just ideal choices (Chiu, Wang, Fang, \& Huang, 2014). This theory was originally developed by Khneman and Tversky (1979) ${ }^{[4]}$ based on the idea that in making choices, consumers tend only to be based their judgments on the potential benefits or losses that might be obtained, but not on the results of these decisions, then they evaluate the losses and benefits obtained using certain heuristics. Because it is often associated with negative consequences, the use of this theory in analyzing perceived risk is still insufficient (Ali, Tan, Pawar, \& Makhbul, 2014; Lu et al., 2005), therefore complexity theory will also be used in this study.

Complexity theory is used to predict consumer response to risk in doing staycation, this theory is able to explain complex, heterogeneous, and nonlinear dynamic processes in various scientific studies. There has been remarkable use of complexity theory upon management science studies, especially marketing in the tourism sector in recent times ${ }^{[4]}$. The use of complexity theory will also be very useful in explaining the complex behavioral responses of consumers (tourists) ${ }^{[4]}$.

\section{METHODOLOGY}

\subsection{Data Collection}

This causal research was conducted quantitatively in order to examine the hypothesis using questionnaires to targeted respondents. The primary data in this research was collected in Indonesia using a convenience sampling method to gain a minimum 240 respondents selected from potential respondents of Indonesians. Samples then drawn from 20 years old Indonesian who domiciled in Indonesia and had done staycation in the past 7 months. Respondent profile categorized as follows:

Table 1 Respondents Profile

\begin{tabular}{|c|c|c|}
\hline \multicolumn{2}{|c|}{ Respondents Profile (249 samples) } & Sample \\
\hline \multirow{2}{*}{ Gender } & Male & $61.8 \%$ \\
\hline & Female & $38.2 \%$ \\
\hline \multirow{4}{*}{ Age } & $20-30$ & $87,6 \%$ \\
\hline & $31-40$ & $9.6 \%$ \\
\hline & $41-50$ & $1.6 \%$ \\
\hline & $>50$ years old & $1.2 \%$ \\
\hline \multicolumn{2}{|c|}{ Respondents Profile (249 samples) } & $\underset{\%}{\text { Sample }}$ \\
\hline \multirow{3}{*}{ Degree } & $\begin{array}{c}\text { Senior } \\
\text { High/Equivalent }\end{array}$ & $16.5 \%$ \\
\hline & Bachelor/Equivalent & $68,3 \%$ \\
\hline & Postgraduate & $5.2 \%$ \\
\hline Monthly & Less than 1.000 .000 & $9.2 \%$ \\
\hline
\end{tabular}




\begin{tabular}{|c|c|c|}
\hline \multirow{4}{*}{ Expenses } & $1.000 .000-2.000 .000$ & $32.9 \%$ \\
\cline { 2 - 3 } & $2.001 .000-3.000 .000$ & $13.3 \%$ \\
\cline { 2 - 3 } & $3.001 .000-4.000 .000$ & $15.3 \%$ \\
\cline { 2 - 3 } & More than 5.000.000 & $29.3 \%$ \\
\hline \multirow{4}{*}{$\begin{array}{c}\text { Frequency } \\
\text { of }\end{array}$} & 1 to twice & $64.3 \%$ \\
\cline { 2 - 3 } \begin{tabular}{c} 
Staycation \\
\cline { 2 - 3 }
\end{tabular} & 3 to 4 times & $24.5 \%$ \\
\cline { 2 - 3 } & 5 to 6 times & $6.02 \%$ \\
\cline { 2 - 3 } & More than 7 times & $5.22 \%$ \\
\hline
\end{tabular}

In identifying the relationship between customer engagement towards customer experience, customer identification, and behavioral intention, this research will use study done by Rather (2020) ${ }^{[9]}$ as reference, hereby the proposed model for this research is:

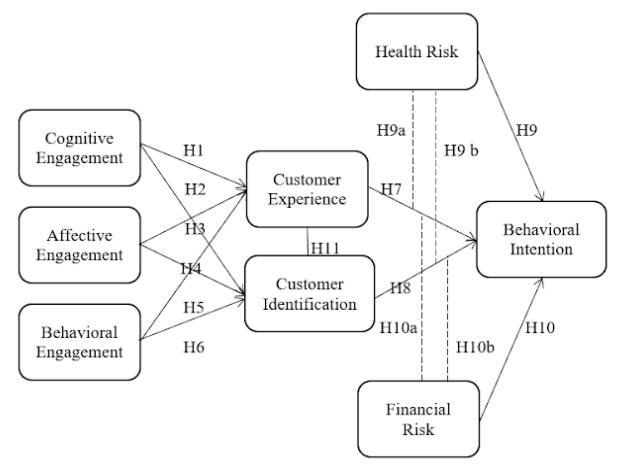

Figure 1 Research Model

Before distributing the questionnaire, a wording test is conducted to five respondents to examine whether the translation used in the questionnaire is already appropriate and easily understood. Then a pre-test was held to 30 respondents to examine the validity and reliability of the study before conducting the main test. Collected pretest data was analysed using IBM SPSS and the multivariate statistics of the main test then finally be analyzed using factor analysis and regression analysis using Sructural Equation Modeling (SEM) tool Lisrel.

\subsection{Survey Instrument}

The survey instrument was compiled using measurement items generated from the literature. The respondents were asked to indicate their recent activities in staycation on a 6-point Likert scale, where 1 implied strongly disagree and 6 gives implication of strongly agree. Item wording was slightly modified and operationalized to suit the context of this study.
To measure customer engagement, the researcher used 10 items ${ }^{[9]}$ to measure the three underlying dimensions of customer engagement (cognitive engagement, affective engagement, behavioral engagement). To assess customer experience, the researcher adapted 12 items drawn from five dimensions of sense, feel, think, act, and relate ${ }^{[9]}$. For behavioral intention the researcher used five items ${ }^{[4][9]}$. To measure customers' perceived risk which are health risk and financial risk adapted, the 7 items in total are used to capture the influence they had on customer behavior in staycation.

\section{RESULTS AND DISCUSSION}

\subsection{Measurement Model}

In determining the accuracy of the variable indicators, the researcher performed a validity test to see whether the data obtained from the preliminary test results are statistically valid. The parameters used by researchers in determining the level of validity of the research engineers are by examining the Kaiser-Meyer Olkin Measure of Sampling Adequacy (KMO) value and the value of the component matrix which each must reach a minimum value of 0.5 , as well as the Bartlett's Test of Sphechirity component which must be smaller from 0.005 . After conducting the validity test, the researcher then continued the reliability test of the pretest results to see the consistency of each indicator in the questionnaire. In this test, researchers used Cronbach's Alpha measurement parameter, where the variable can be said to pass if it exceeds the value of 0.6.

Table 2 Validity and Reliability Test

\begin{tabular}{|c|c|c|}
\hline Variable & Validity & Reliability \\
\hline CE & After removing CE3 & Reliable \\
\hline VEriable & Validity & Reliability \\
\hline BE & After removing AE4 & Reliable \\
\hline CX & Valid & Reliable \\
\hline CI & After removing CI2 & Reliable \\
\hline BI & Valid & Reliable \\
\hline HR & Valid & Reliable \\
\hline FR & Valid & Reliable \\
\hline
\end{tabular}




\subsection{Structural and Hypothesis Testing}

Table 3 Hypothesis Test

\begin{tabular}{|c|c|c|c|}
\hline & Path & t-value & Evaluation \\
\hline H1 & CE $\rightarrow$ CX & 2.25 & Supported \\
\hline H2 & CE $\rightarrow$ CI & -8.36 & Rejected \\
\hline H3 & AEt $\rightarrow$ CX & 5.13 & Supported \\
\hline H4 & AE $\rightarrow$ CI & -12.54 & Rejected \\
\hline H5 & BE $\rightarrow$ CX & -8.63 & Rejected \\
\hline H6 & BE $\rightarrow$ CI & 26.09 & Supported \\
\hline H7 & CX $\rightarrow$ BI & 0.66 & Rejected \\
\hline H8 & CI $\rightarrow$ BI & 19.36 & Supported \\
\hline H9 & HR $\rightarrow$ BI & 11.25 & Rejected \\
\hline H9a & CX_HR $\rightarrow$ BI & -2.01 & Supported \\
\hline H9b & CI_HR $\rightarrow$ BI & -20.22 & Supported \\
\hline H10 & FR $\rightarrow$ BI & 2.87 & Rejected \\
\hline H10a & CX_FR $\rightarrow$ BI & 0.74 & Rejected \\
\hline H10b & CI_FR $\rightarrow$ BI & 2.8 & Rejected \\
\hline H11 & CX $\rightarrow$ CI & 1.44 & Rejected \\
\hline
\end{tabular}

From the results of hypothesis testing, there are several hypotheses are accepted (H1, H3, H6, H8, H9a, H9b). The parameter values indicate that there are significant positive relationships between cognitive engagement, and affective engagement to customer experience; behavioral engagement to customer identification and between customer identification toward behavioral intention. Besides, result shows that there are significant negative relationship between health risk as moderating variables from customer experience and customer identification. This means that the more engaged the consumers (tourists) are cognitively and affectively, the more likely they will have a good experience. This is in accordance with prior research ${ }^{[9]}$ where cognitive and affective engagement has a significant relationship which has a positive effect on customer experience. The same conditions also applied within relationship from behavioral engagement to customer identification and customer identification toward behavioral intention.

However, the researchers found contrary results in assumed hypothesis and the research findings. These may resulted from the conditions when the research is taken, which is during pandemic. During the pandemic, respondents will face various limitations and restrictions due to regulations applied. This conditions will obviously affect the engagement customer had during their staycations. The lower engagement customer had compared to engagement during normal situations affected their customer co-experience and customer identification.

On the other hand, based on cross tabulation test on customers' profile, the researchers also found that the low engagement (especially behavioral engagement) during customers' staycation are also depicted in their frequency and duration of their staycation. Various factors such as age, average monthly spending, and domicile plays a significant role as driver in customers' staycation trips.

In addition, rejected hypotheses on health risk and financial risk might be seen from customer behavior perspective. Positive significant result from health risk toward behavioral intention in staycation during pandemic shows increased level of health risk and financial will eventually increase customers' effort in finding information regarding their staycation. Customers will intrigued to find adequate information in order to cover their concern on both health risk and financial risk. If done properly, this behavior will certainly increase their trust level toward staycation and finally will decide to do a staycation amidst pandemic. Another behavior to be considered from the result is also depicted in the respondents' profile, where almost $40 \%$ the respondents preferred to do staycation with their families in a leisure trips. During family leisure, the tolerance level of customers' on their budget will be scratchy. This means that they already prepared for the financial risk upon their staycations trips.

\section{CONCLUSION AND FURTHER RESEARCH}

\subsection{Implications}

Based on the results of this study, stakeholders in the tourism sector can prepare various risk-reduction strategies (such as preparing CHSE certification) and in particular, stakeholders in domestic tourism can prepare several staycation programs tailored to the capabilities and needs of their respective regions. The variety of staycation program packages can be adjusted according to the purpose of the staycation trip (leisure, well-being, recreation, etc.) to meet customers' needs and wants. Another adjustment such as pricing and accommodation based on analysis of target consumers will also be beneficial to be implemented. Staycation has proven to be able to help the tourism sector rise during the 2008 economic crisis in America, and with the current limitations on mobility, it should also be an alternative solution for tourism stakeholders. Not only as an alternative during a pandemic, but with the potential it has, a development and improvement prepared for 
staycation programs can help improve the local economy even after the pandemic.

According to the research findings, the tourism stakeholders have to increase and improve the level of engagement, especially behavioral engagement in their offerings for domestic tourist in staycation trips. This improvement in engagement will increase the level of customer experience and customer identification which eventually will lead to customer behavioral intention if it is has adequate level of strategic programs to overcome health risk.

\subsection{Limitations and Future Research}

In conducting this research, the researcher found several limitations such as the possibility of giving inappropriate translation in the questionnaire that might give confusion for respondents, and also there are two indicators that were not used by the researchers since they showed invalid values during pretest. Besides there is no regional specifications for conducting the research in Indonesia. This can be done in further studies to see the potential and capabilities each area has to welcome tourists with their offerings. In addition, researchers also did not consider differences in drivers that motivate customers to do a staycation (such as lifestyle). Further research can be done by considering the drivers in order to have better understanding in preparing suitable packages that can be beneficial practically for businesses stakeholders. This research is also did not consider the different between first-time and repeatcustomers. This consideration may suggest different insight that might be valuable for tourism stakeholders. Additionally, future research can also develop this study after the pandemic in different circumstances such as vacation in Indonesia instead of staycation.

\section{AUTHORS' CONTRIBUTIONS}

R.O. carried out the research. N.S. supervised the process and the findings of this work. All authors provided critical feedback and helped shape the research and analysis.

\section{ACKNOWLEDGMENTS}

This research would not have been possible without the support of my supervisor, Dr. Nurdin Sobari. His knowledge and attention to detail kept my work on track from the beginning until the final draft of this research.

\section{REFERENCES}

[1] World Health Organization, What We Know About COVID-19 Vaccine Development: The Latest on The Covid-19 Global Situation \& Vaccine Development, 2020: www.who.int/epi-win

[2] Fatma Altuntas Mehmet Sahin Go, The Effect of Covid-19 Pandemic on Domestic Toursim: A DEMATEL Method Analysis on Quarantine Decisions, 2020

[3] Rather, R. Hollebeek, L., Experiential Marketing for Tourism Destinations, In: Dixit, (S. (Ed.), Routledge Handbook of Tourism Experience Management and Marketing (pp:271-282), Routledge Publishing House

[4] Hossein G.T. Olya, Amr Al Ansi (2018), Risk Assessment of Halal Products and Services: Implication for Tourism Industry, Journal of Tourism Management, DOI: 10.1016/j.tourman.2017.10.015

[5] Pan, Shu-Yuan \& Gao, Mengyao \& Kim, Hyunook \& Shah, Kinjal \& Pei, Si-Lu \& Chiang, Pen-Chi. (2018). Advances and challenges in sustainable tourism toward a green economy. The Science of the total environment. 635. 452-469. 10.1016/j.scitotenv.2018.04.134.

[6] World Tourism Organization (2017). UNWTO Tourism Highlights: 2017 Edition, UNWTO, Madrid,

DOI:

https://doi.org/10.18111/9789284419029

[7] Marianna Sigala, Tourism and Covid-19: Impacts and Implications for Advancing and Resetting Industry and Research, Journal of Business Research, DOI: 10.1016/j.jbusres.2020.06.015

[8] James, Alexandra \& Ravichandran, Swathi \& Chuang, Ning Kuang \& III, Edward. (2016). Using Lifestyle Analysis to Develop Lodging Packages for Staycation Travelers: An Exploratory Study. Journal of Quality Assurance in Hospitality \& Tourism. 1-29. 10.1080/1528008X.2016.1250240.

[9] Raouf Ahmad Rather (2020) Customer Experience and Engagement in Tourism Destinations: The Experiential Marketing Perspective, Journal of Travel \& Tourism Marketing, 37:1, 15-32, DOI: 10.1080/10548408.2019.1686101

[10] David Clarke et. al (2018), Experience is Everything: Here's How to Get It Right, PWC (2018)

[11] Brakus, J.J., Schmitt, B. H., \& Zarantonello, L. (2009) Brand Experience: What Is It? How Is It 
Measured? Does It Affect Loyalty? Journal of Marketing, 73 (3), 52-68

[12] Michelle, Customer Experience vs Customer Engagement: Two Sides of a Very Valuable Coin, 2018, https://freshdesk.com/customerengagement/customer-experience-vs-customerengagement-blog/

[13] Hasan, Md \& Ismail, Ahmed \& Islam, Faridul. (2017). Tourist Risk Perceptions and Revisit Intention: A Critical Review of Literature. Cogent Business \& Management. 4. 10.1080/23311975.2017.1412874.

[14] Bernd Schmitt (1999) Experiential Marketing, Journal of Marketing Management, 15: 1-3, 53-67, DOI: $10.1362 / 026725799784870496$ 